\title{
An Autochthonous Human Case of Fasciolopsiasis in Nepal
}

\author{
Ranjit Sah ${ }^{1,2}$, Michele Calatri ${ }^{3}$, Rafael Toledo ${ }^{4, *}$ \\ ${ }^{1}$ Department of Microbiology, Tribhuvan University Teaching Hospital, Institute of Medicine, Kathmandu, Nepal; ${ }^{2}$ Department of Medicine (Division of \\ Infectious Disease), Medanta, The Medicity, Gurugram, Haryana, India; ${ }^{3}$ University of Cagliari-Faculty of Medicine and Surgery, Cagliari, Italy; ${ }^{4}$ Area \\ de Parasitología, Departamento de Farmacia, Tecnología Farmacéutica y Parasitología, Facultad de Farmacia, Universidad de Valencia, Av. Vicent \\ Andrés Estellés s/n, 46100 Burjassot, Valencia, Spain
}

\begin{abstract}
Fasciolopsiasis is rarely known as the parasitic disease in Nepal. Herein, we report a case of fasciolopsiasis in a 22-year-old man who was admitted in the hospital with abdominal pain, distension and loss of appetite for a month. He had previously diagnosed with acute viral hepatitis but, his abdominal pain was not resolving despite improvement in his liver function and general condition. During endoscopy an adult digenean worm was seen in the first part of the duodenum. After isolation, the worm was identified morphologically as Fasciolopsis buski. Microscogic examination of the patient's stool revealed eggs with a morphology consistent with F. buski. Eggs were yellow-brown, ellipsoidal, unembmbryonated, operculated, filled with yolk cells, with thin shell and ranging 118-130 $\mu \mathrm{m}$ in length and 60-69 $\mu \mathrm{m}$ in width. The abdominal pain of the patient was resolved after treatment with praziquantel. By the present study, it was confirmed for the first time that fasciolopsiasis is indigenously transmitted in Nepal. Accordingly, the epidemiological studies in humans and reservoir host animals should be performed intensively in near future.
\end{abstract}

Key words: Fasciolopsis buski, fasciolopsiasis, abdominal pain, hepatitis, Nepal

\section{INTRODUCTION}

Fasciolopsiasis is caused by the infection of a species of zoonotic digenean trematode, Fasciolopsis buski, which is the only 1 species within the genus Fasciolopsis. It is a foodborne disease associated with the consumption of water plants. The life cycle of F. buski is comprised of 2 hosts, a vertebrate definitive host and an aquatic snail intermediate host (commonly of the genera Segmentina or Hippeutis). Humans become infected by ingesting metacercariae on the aquatic plants. The adult worm lives attached to the duodenal and jejunal mucosa where it may grow up to $100 \mathrm{~mm}$ of length and $30 \mathrm{~mm}$ of width. Because of this remarkable size it is commonly known as the giant intestinal fluke [1,2]. The eggs are released (about 25,000 eggs/day) in the freshwater with the faeces and miracidia hatch in 3-7 weeks [2,3].

WHO includes the fasciolopsiasis along with the other

\footnotetext{
- Received 21 February 2019, revised 1 April 2019, accepted 10 April 2019.

*Corresponding author (rafael.toledo@uv.es)

(c) 2019, Korean Society for Parasitology and Tropical Medicine

This is an Open Access article distributed under the terms of the Creative Commons Attribution Non-Commercial License (http://creativecommons.org/licenses/by-nc/4.0) which permits unrestricted non-commercial use, distribution, and reproduction in any medium, provided the original work is properly cited.
}

foodborne trematodiases in its special program for the neglected zoonotic diseases, a subset of neglected tropical diseases which require a special integrated approach to control and elimination, in both humans and animals [2]. However, it is evident that even inside the group of trematode foodborne infections, the available data on distribution and prevalence of the various parasites have conspicuous differences. The most recent report on the global burden of these helminthiases estimated a worldwide number of people infected with intestinal flukes of about 6.7 million [4], but specific data on fasciolopsiasis remains not available and its real impact on the public health, society and economy of the endemic countries is still unclear [5]. A lot of human fasciolopsiasis cases have been reported in the adjacent countries including India, but only one case was reported in Nepal. However, this trematodiasis has been prevalent in cattle in Nepal $[1,2,5-7]$. Therefore, we are going to describe the additional one case of fasciolopsiasis in Nepal in this study.

\section{CASE REPORT}

On October 2016, a 22 years old man from the city of Kalaiya, Bara district in the South-Eastern Nepal was admitted in 
the Department of Medicine (gastroenterology) of the Tribhuvan University Teaching Hospital, in Kathmandu. The patient showed abdominal pain and distension with loss of appetite for a month. The patient had received a previous diagnosis with acute hepatitis $\mathrm{B}(\mathrm{HBsAg}+)$. At clinical examination at the admission, the patient showed jaundice and looked ill. The abdominal ultrasonography revealed hepatomegaly with altered echotexture of the liver and ascites. Haematological tests showed high blood levels of bilirubin (total $525 \mu \mathrm{mol} / \mathrm{L}$, direct $342 \mu \mathrm{mol} / \mathrm{L}$ ) and liver enzymes (AST $163 \mathrm{U} / \mathrm{L}$, ALT 300U/

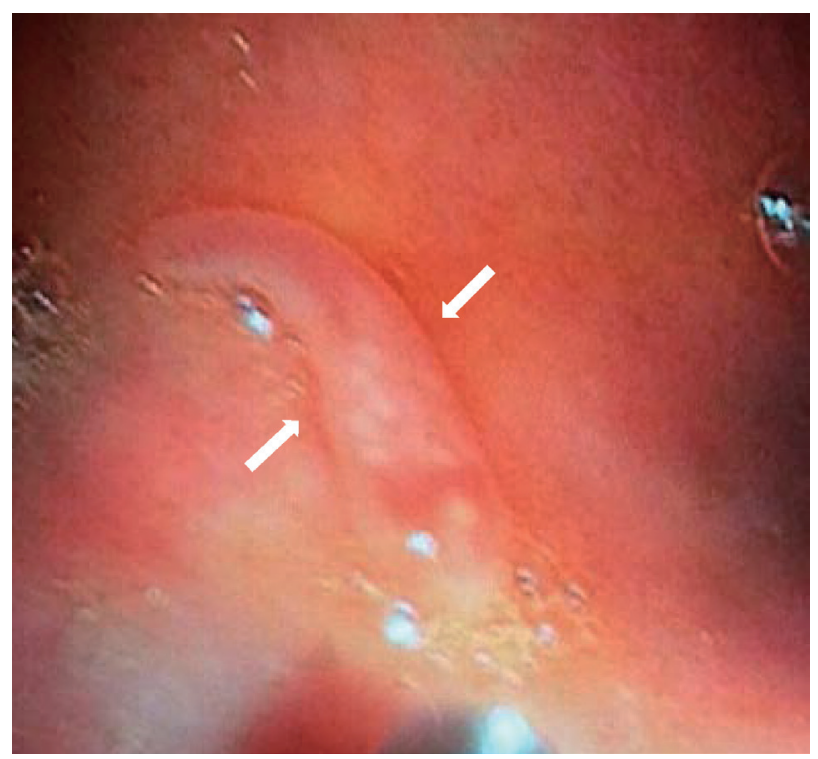

Fig. 1. Endoscopic image of the first part of duodenum showing a living worm, Fasciolopsis buski (between arrows).
L, Alkaline phosphatase $122 \mathrm{U} / \mathrm{L}$, Gamma-Glutamyl Transferase $79 \mathrm{U} / \mathrm{L})$ and a decreased value of albumin $(25.0 \mathrm{gm} / \mathrm{L})$. After supportive management, his general condition and liver function got improved but his abdominal pain was persisting. He had not traveled outside Nepal due to his low-economic condition and gave the history of eating aquatic plants and snails from ponds and rivers near his home. He was afebrile with no local tenderness in the abdomen. An upper gastrointestinal endoscopy was prescribed to evaluate a suspected portal hypertensive gastropathy in relation to the abdominal pain. The procedure revealed a mild gastropathy of fundus, body and antrum of the stomach with a live whitish flat worm in the first part of the duodenum (Fig. 1). Once removed, the macroscopic examination of the specimen, studied in fresh, was suggestive of Fasciolopsis buski. The recovered worm was flat, leaf-like, about $70 \times 20 \mathrm{~mm}$ in size with pointed anterior and blunt posterior ends. The oral sucker $2 \mathrm{~mm}$ in diameter, in the anterior end and smaller than the ventral sucker. The ventral sucker was well developed, and measuring $4-5 \mathrm{~mm}$ in diameter. Anterior segment of the worm showed the uterus filled with the plenty of eggs and middle segment showing shell glands and ovary (Fig. 2A, B). It could be distinguished from other fasciolids by a lack of cephalic cone or "shoulders", the unbranched ceca and the site of infection. Coprological examination of the patient allowed to detect eggs with a morphology consistent with F. buski. Eggs were yellow-brown, ellipsoidal, unembmbryonated, operculated, filled with yolk cells, with thin shell and ranging 118-130 $\mu \mathrm{m}$ in length and 60-69 $\mu \mathrm{m}$ in width (Fig. 2C). The images of both the adult
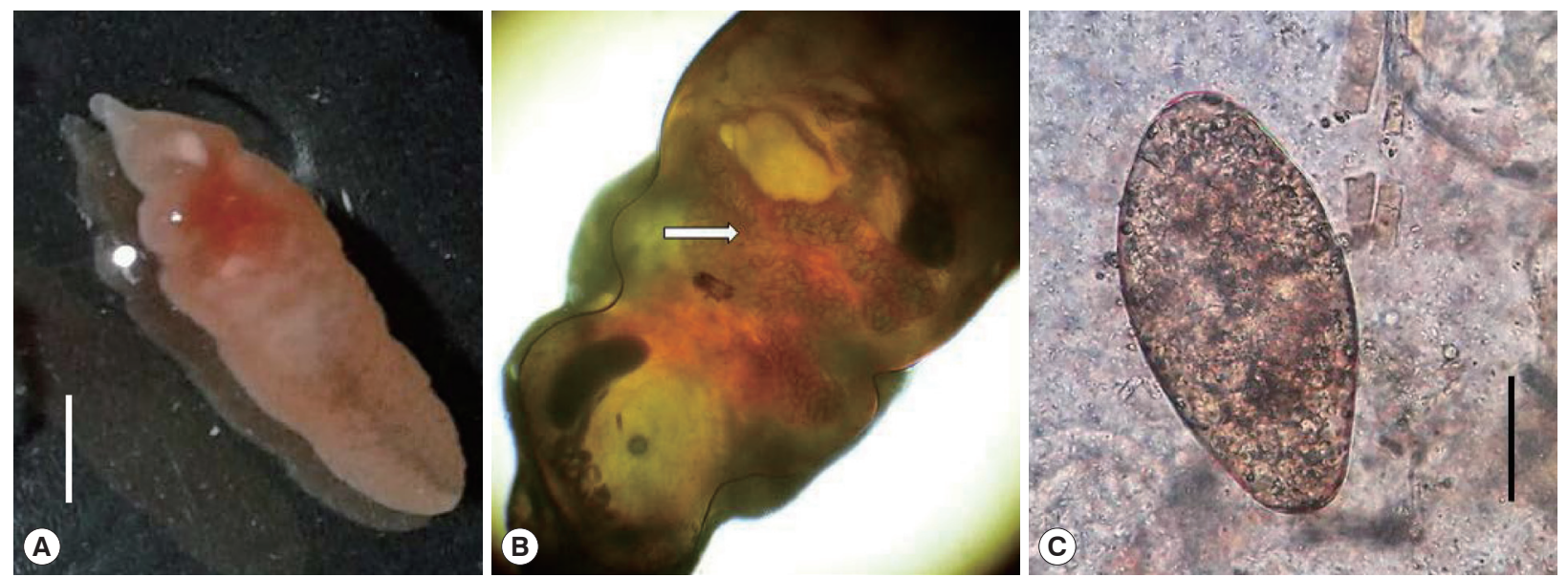

Fig. 2. (A) An adult Fasciolopsis buski collected from the intestine. Scale bar $=30 \mu \mathrm{m}$. (B) Adult Fasciolopsis buski showing the uterus filled with eggs (arrow). Cephalic cone or "shoulders" was not observed at anterior end of the body. (C) An egg of Fasciolopsis buski in a stool smear of the patient. Scale bar $=30 \mu \mathrm{m}$. 
worm and the eggs were sent to the CDC laboratory in Atlanta for confirmation. Few days later the DPDx CDC team confirmed the finding. The patient was managed conservatively for the viral hepatitis and with praziquantel $(75 \mathrm{mg} / \mathrm{kg} /$ day orally in 3 divided doses for 1 day) for the parasitic infection. Follow up after one month revealed no eggs of $F$. buski in stools with resolution of the abdominal pain and improvement in liver function test.

\section{DISCUSSION}

Fasciolopsiasis is known to be endemic in freshwater habitats of Cambodia, China, the Indian subcontinent, Laos, Myanmar, Taiwan, Thailand and Vietnam [1,6]. The disease occurs focally and linked to freshwater habitats associated with common social and agricultural practices and promiscuous defecation [2]. Humans commonly become infected by eating raw or undercooked aquatic plants, but infection can be also contracted by the drinking or use of contaminated water or processing of the water-derived plants, e.g., using teeth to peel plants.

The present case is the second report of F. buski human infection, but the first case of autochthonous transmission in Nepal. Dutt et al. [7] reported a case of fasciolopsiasis in a 14 months-old child resident of Terai (Far Western) region of Nepal. Although stool routine examination of the child was negative, the patient coughed out a live adult worm after antihelminthic treatment. The authors suggested that infection was imported and related to drinking water from a pond during a stay of the child in India. The case presented herein appears to be the first reported case of autochthonous transmission of $F$. buski in Nepal and related to the habit of the patient to eating aquatic plants and snails from ponds and rivers near his home, which suggest the presence of this parasite in Nepal. The ingestion of aquatic vegetables is a common source of human infection [6].

The low number of cases of human fasciolopsiasis in Nepal is surprising since this country has been qualified as probably endemic area of foodborne trematode infections [8] and, moreover, human cases of Fasciolopsis buski have been described from the Nepal bordering states of Bihar and Uttar Pradesh in India [9-11]. Probably, the impact of human fasciolopsiasis in Nepal is underestimated in relation to the vague and unspecified symptoms of most light infections with F. bus$k i$ and the poor development of health systems in developing countries, especially in the remote rural environments [2]. The severity of the disease is usually directly associated with the number of parasites involved: an infection with one or few worms may be subclinical but a heavy parasitic load can lead to severe tissue damage and complications such as ulcerations, abscesses and hemorrhages with the eventuality of intestinal obstruction and perforation $[1,3]$. When present, symptoms include abdominal pain, nausea, diarrhea and headache, while marked eosinophilia, leukocytosis and B12 deficiency are common reports only in severe infections [3]. Allergic reaction to the toxic metabolites of the worm may manifest as facial-orbital edema, and anasarca [3,6]. The diagnosis is usually suggested by the clinical presentations in endemic areas and confirmed by detecting the ellipsoidal, yellowish-brown, large $(130-140 \times 85 \mu \mathrm{m})$, thin shell, operculated eggs in the stool $[2,3]$. It should be noted that the eggs of $F$. buski are almost indistinguishable from those of Fasciola species (F. hepatica and $F$. gigantica) $[5,12,13]$, and those of other lesser common intestinal trematode such as Echinostoma ilocanum [14], making necessary further investigations in areas where these parasites overlaps. In our case, identification of the adult worm was made on the basis of morphological keys and its differences with F. hepatica are evident, specifically, F. buski lacks the cephalic cone and is usually longer [3].

This report of $F$. buski in Nepal raises questions and issues that need to be investigated. Our report shows that active transmission of F. buski are occurring in Nepal. Thus, chronic abdominal pain should be investigated for the parasitic infection and treated accordingly. Socio-environmental background of the rural areas of the country may be a suitable scenario for the emergence of this parasite whose impact can be underestimated. Further studies can help to understand the current occurrence of fasciolopsiasis in Nepal and to assess its impact on public health.

\section{ACKNOWLEDGMENTS}

We would like to thank DPDx Diagnosis team (Parasitology) of CDC, Atlanta GA, USA for the confirmation of our diagnosis. Work was supported by the Projects BFU2016-75639-P from the Ministerio de Economía y Competitividad (Spain), and No. RD12/0018/0013, Red de Investigación Cooperativa en Enfermedades Tropicales-RICET, IV National Programe of I+D+I 2008-2011, ISCIII-Subdirección General de Redes y Centros de Investigación Cooperativa and FEDER from the 
Ministerio de Sanidad y Consumo (Spain). Thanks are given to Dr. Shushila Khadka, Dr. Samikshya Neupane, Dr. Sagar poudyal, Dr. Rabin Hamal, Dr. Mohan Khadka, Dr. Ranjana Sah, Dr. Sanjit Sah, Prof. Dr. Basista Rijal, Prof. Dr. Bharat Mani Pokhrel, Prof. Dr. Jeevan Bahadur Sherchand, Prof. Keshab Parajuli, Hari Parsad Kattel and Associated Prof. Niranjan Prasad Sah for their constant support.

\section{CONFLICT OF INTEREST}

The authors declare that they have no competing interests.

\section{REFERENCES}

1. Keiser J, Utzinger J. Food-borne trematodiases. Clin Microbiol Rev 2009; 22: 466-483.

2. Graczyk TH, Gilman RH, Fried B. Fasciolopsiasis: is it a controllable food-borne disease? Parasitol Res 2001; 87: 80-83.

3. Garcia LS. Diagnostic Medical Parasitology. 5th ed. Washington DC, USA. ASM Press. 2007, pp 411-416.

4. Fürst $\mathrm{T}$, Keiser J, Utzinger J. Global burden of human food-borne trematodiasis: a systematic review and meta-analysis. Lancet Infect Dis 2012; 12: 210-221.

5. Achra A, Prakash P, Shankar R. Fasciolopsiasis: Endemic focus of a neglected parasitic disease in Bihar. Indian J Med Microbiol 2015; 33: 364-368.

6. Chai JY, Shin EH, Lee SH, Rim HJ. Foodborne Intestinal Flukes in Southeast Asia. Korean J Parasitol. 2009; 47 (suppl): 69-102.

7. Dutt Pant N, Sharma M, Khatiwada S. Fasciolopsis buski vomited out by a child; the first case reported from Nepal. Nepal J Biotechnol 2015; 3: 66-67.

8. Devleesschauwer B, Ale A, Torgerson P, Praet N, Maertens de Noordhout C, Pandey BD, Pun SB, Lake R, Vercruysse J, Joshi DD, Havelaar AH, Duchateau L, Dorny P, Speybroeck N. The burden of parasitic zoonoses in Nepal: a systematic review. PLoS Negl Trop Dis 2014; 8: e2634.

9. Kumari N, Kumar M, Rai A, Acharya A. Intestinal trematode infection in North Bihar. JNMA J Nepal Med Assoc 2006; 45: 204206.

10. Rai S, Wadhwa V, Kharbanda P, Uppal B. A case of poly-parasitism involving a trematode and four different nematodes in a migrant from Bihar. Indian J Med Microbiol 2007; 25: 62-63.

11. Mahajan RK, Duggal S, Biswas NK, Duggal N, Hans C. A finding of live Fasciolopsis buski in an ileostomy opening. J Infect Dev Ctries 2010; 4: 401-403.

12. Sah R, Khadka S, Lakhey PJ, Pradhan S, Shah NP, Singh YP, MasComa S. Human Case of Fasciola gigantica-like infection, review of human fascioliasis reports in Nepal, and epidemiological analysis within the South Central Asia. Acta Parasitologica 2018; 63: 435-443.

13. Sah R, Khadka S, Khadka M, Gurubacharya D, Sherchand JB, Parajuli K, Shah NP, Kattel HP, Pokharel BM, Rijal B. Human fascioliasis by Fasciola hepatica: the first case report in Nepal. BMC Res Notes 2017; 10: 439.

14. Sah R, Khadka S, Hamal R, Poudyal S. Human echinostomiasis: a case report. BMC Res Notes 2018; 11: 17. 